|| ISSN(online): 2589-8698 || ISSN(print): 2589-868X ||

International Journal of Medical and Biomedical Studies Available Online at www.ijmbs.info

NLM (National Library of Medicine ID: 101738825)

Index Copernicus Value 2019: 79.34

Review Article

Volume 5, Issue 9; September: 2021; Page No. 43-51

\title{
FACTORS RESTRICT TREATMENT EFFICIENCY IN ASTHMA PATIENTS
}

Dr. Khaled Hassan ${ }^{1}$, Asmaa Alsehli ${ }^{2}$, Nouf hijji ${ }^{3}$, Faisal Alsumairi ${ }^{4}$, Sultan Alhumaid ${ }^{5}$, Khaled Aldraihem ${ }^{5}$, Mohammad Alkraidees $^{5}$, Ghada Alduraye ${ }^{5}$, Saud Dhafer Alshahrani ${ }^{6}$, Mohammad Aladwani ${ }^{7}$, Zainab Al Omran ${ }^{8}$, Turki Alzibali ${ }^{9}$, Fisal Haobani $^{10}$, Yousef Almutairi ${ }^{11}$, Abdulatif Albassam ${ }^{11}$, Mashari Alassaf ${ }^{10}$

${ }^{1}$ Consultant Family Medicine, Saudi Arabia.

${ }^{2}$ Taibah University, Saudi Arabia.

${ }^{3}$ Umm Al Qura University, Saudi Arabia.

${ }^{4}$ Taif University, Saudi Arabia.

${ }^{5}$ King Saud bin Abdulaziz University for Health Sciences, Saudi Arabia.

${ }^{6}$ University of Bisha, Saudi Arabia.

${ }^{7}$ Jordan University of Science and Technology, Jordan.

${ }^{8}$ King Faisal University, Saudi Arabia.

${ }^{9}$ King Abdulaziz University Rabigh Branch, Saudi Arabia.

${ }^{10}$ Vision Colleges, Saudi Arabia.

${ }^{11}$ Dar Al Uloom, Saudi Arabia.

Article Info: Received 10 July 2021; Accepted 29 August 2021

DOI: https://doi.org/10.32553/ijmbs.v5i9.2183

Corresponding author: Dr. Khaled Hassan

Conflict of interest: No conflict of interest.

\section{Abstract}

Background: A number of modifiable factors that contribute to poor asthma control have been identified. We wanted to know how many patients had insufficient therapy, adherence, or major inhaler technique errors, and how they affected asthma control. Methodology: We conducted a cross-sectional multicenter observational research with asthma patients who were referred for the first time from primary to specialized treatment. Adequate prescription according to guidelines, treatment adherence, and illness control were among the data collected. 35.9\% of the 1682 patients (age $45-17$ years, 64.6 percent men) had insufficient prescriptions, $76.8 \%$ had low adherence, and 17 percent had critical inhaler technique errors, with Easyhaler users making significantly fewer critical errors than other dry powder inhaler users ( 10.3 versus $18.4 \% ; p 0.05)$. Inadequate prescription (OR: 3.65), non-adherence to therapy (OR: 1.8), and inhaler abuse were all linked to poor asthma control (OR: 3.03). A greater number of risk variables were linked to a greater likelihood of having poorly managed asthma.

Keywords: Asthma, interdental cleaning, elderly, prevention, periodontal disease, caries.

\section{Introduction}

Asthma is a frequent disease that costs a lot of money in terms of healthcare and lost productivity [1]. Asthma is becoming more common around the world, with about 1000 people dying from it every day, according to a study published in 2015 [2]. According to the most recent data on asthma prevalence worldwide, 334 million people are affected [3]. However, its frequency varies widely between countries, with wealthy countries having the highest prevalence1. Exacerbations are associated with high direct (medications, hospitalization, Emergency Department treatment, etc.) and indirect (school absenteeism, loss of work productivity, etc.) costs. Asthma exacerbations are currently one of the most common reasons of Emergency Department4 visits, highlighting asthmatic patients' poor management. Exacerbations can be caused by a variety of circumstances, including exposure to external stimuli, poor adherence to medication, inadequate therapy, and poor inhaler technique in the case of uncontrollable asthma [4-6]. Several studies have found that asthmatic patients had poor medication adherence: 50 percent in children and 30-70 percent in adults, depending on the nation, age, sex, and ethnicity $[7,8]$. Limited understanding or recognition (among patients and/or physicians), beliefs or side effect worries, inhaler features, and directions for use were all factors that contributed to this difference. As a result, asthma control as a therapeutic goal is still a long way off [9]. Better control would improve not only cost effectiveness but also quality of life, lower school absenteeism, and boost workplace productivity. The same problem can be seen in asthma management in primary care. Several research on asthma in primary care appear to imply that, despite accessible medications, asthma control in practical practice is inadequate. European publications [10,11]. have revealed little apparent improvement in symptom control in recent years. The study's primary goals are to (1) determine the appropriateness of prescribed treatment, as well as the presence of poor adherence and critical errors in inhalation technique in patients referred from primary care to a specialist for the first time, and (2) investigate the 
relationship between these factors and poor asthma control. This real-life study could help us figure out whether asthma management in primary care has improved in terms of prescription quality, inhaler technique, and patient adherence to treatment in the 30 years since asthma guidelines were implemented in Spain [13-17].

\section{Material and Methods}

\section{Participants and Study Design}

Patients aged 18 years who used any type of inhaler device and were referred from general care to a pneumologist or allergologist for the first time for any reason were included in a cross-sectional multicenter observational study. From September through December 2016, data was gathered. The lack of a signed informed permission and incapacitating illness or mental disease were also exclusion criteria, making participation in the study impossible according to the research requirements. Spirometry and a bronchodilator test were performed on all patients to confirm or rule out asthma [19-24].

\section{Study Measurements}

The following important characteristics were evaluated: adequate asthma therapy based on GINA recommendations44 (GINA treatment steps 1-5 were used to determine the appropriateness of current patients' treatment based on asthma control at the time of the visit). Treatment adherence according to the MG questionnaire (patients were classified into reliable or not reliable according to a punctuation from 0 to 4 , with $0=$ reliable and $1=$ not reliable)45,46, adherence to inhalers (TAI 50 reliable; 50 not reliable) 45,46 , adherence to inhalers (TAI 50 reliable; 50 not reliable) 45,46 , adherence to inhalers (TAI 50 reliable; 50 not reliable)45,46, adherence to inhalers. item 12 of the TAI questionnaire revealed severe issues with patient inhaler technique. Only the primary inhaler was tested for maintenance therapy. This item includes a realistic demonstration of patients' inhaler technique as well as the physician identifying crucial faults. This item depicts two types of patients: those with one critical mistake and those without. A questionnaire from the GEMA teaching material was used to assess additional patient knowledge about asthma (Supplementary Table 3) [25-27].

Asthma severity according to the 2015 GINA criteria44, comorbidities (allergy, occupational exposure to allergens or irritants, smoking, etc.), and asthma control according to both GINA and ACT criteria44,48 were all gathered. These factors, according to GINA, were considered: Symptoms of the patients throughout the day and at night (two times per week for daytime symptoms and no nocturnal symptoms). As a result, patients were divided into two groups: wellcontrolled (all previous items) and partially/not-controlled (one to four previous things). Patients were divided into the same two categories by the ACT, but this time through five items from the validated Spanish version of the ACT (21: well controlled, 21: partially/not controlled). All data was gathered in a single visit using an online patient notebook that was suited to the study's needs. The study was approved by the Ethics Committee (Hospital Clinic de Barcelona, Registration number HCB/2016/0647), and it was carried out in accordance with the Helsinki Declaration (1964). All participants gave their informed consent [29-35].

\section{Statistical Analysis}

For categorical data, the Pearson's chi-squared test (2) was used, and for continuous data, the analysis of variance test was used. To establish the independence of discovered components, a binary logistic regression was performed (OR). Cohen's k coefficient, Spearman's correlation coefficient, and $\mathrm{R}$ square were used to express the relationship and concordance between ACT/GINA regarding asthma control (R2). SPSS 20.0 was used to analyze all of the data [35-40].

\section{Results}

\section{Demographics and Clinical Characterization}

The trial involved 1682 patients, with men accounting for 64.6 percent of the total. The average age was 45 years and 17 months. Table 1 summarizes the cohort's characteristics [41-45].

Table 1: Baseline demographic and clinical characteristics. From: Prevalence of modifiable factors limiting treatment efficacy of poorly controlled asthma patients: EFIMERA observational study

\begin{tabular}{|c|c|c|}
\hline Variable & Results & Number of patients evaluated \\
\hline Age (years), mean \pm SD (range) & $45.2 \pm 17.9(18-90)$ & 1681 \\
\hline Females, $n(\%)$ & $592(35.4)$ & 1670 \\
\hline Males, $n(\%)$ & $1078(64.6)$ & 1670 \\
\hline Age at diagnosis (years), mean $\pm S D$ & $33.8=15.7$ & 1682 \\
\hline Disease duration (years), mean $\pm \mathrm{SD}$ & $14.9 \pm 14.1$ & 1682 \\
\hline Time between treatment initiation and diagnosis (years), mean $\pm \mathrm{SD}$ & $1.1 \pm 6.6$ & 1677 \\
\hline Current smokers, $n(\%)$ & $263(15.7)$ & 1678 \\
\hline Ex-smoker, $n(9)$ & 294 (20.8) & 1414 \\
\hline Any allergy, $n(\%)$ & $665(39.8)$ & 1671 \\
\hline Any comorbidity, $n(\%)$ & $841(50.4)$ & 1668 \\
\hline Obesity, $n(\%)$ & $242(14.5 \%)$ & 1668 \\
\hline Rhinosinusitis. $n(\%)$ & $190(11.496)$ & 1668 \\
\hline Rhinitis/conjunctivitis, $n(\%)$ & $313(18.8 \%)$ & 1668 \\
\hline Gastroesophageal reflux disease, $n(\%)$ & $149(8.9 \%)$ & Activate Windows \\
\hline Other comorbidities, $n(9)$ & $268(16.1)$ & Go to settings to activat \\
\hline
\end{tabular}




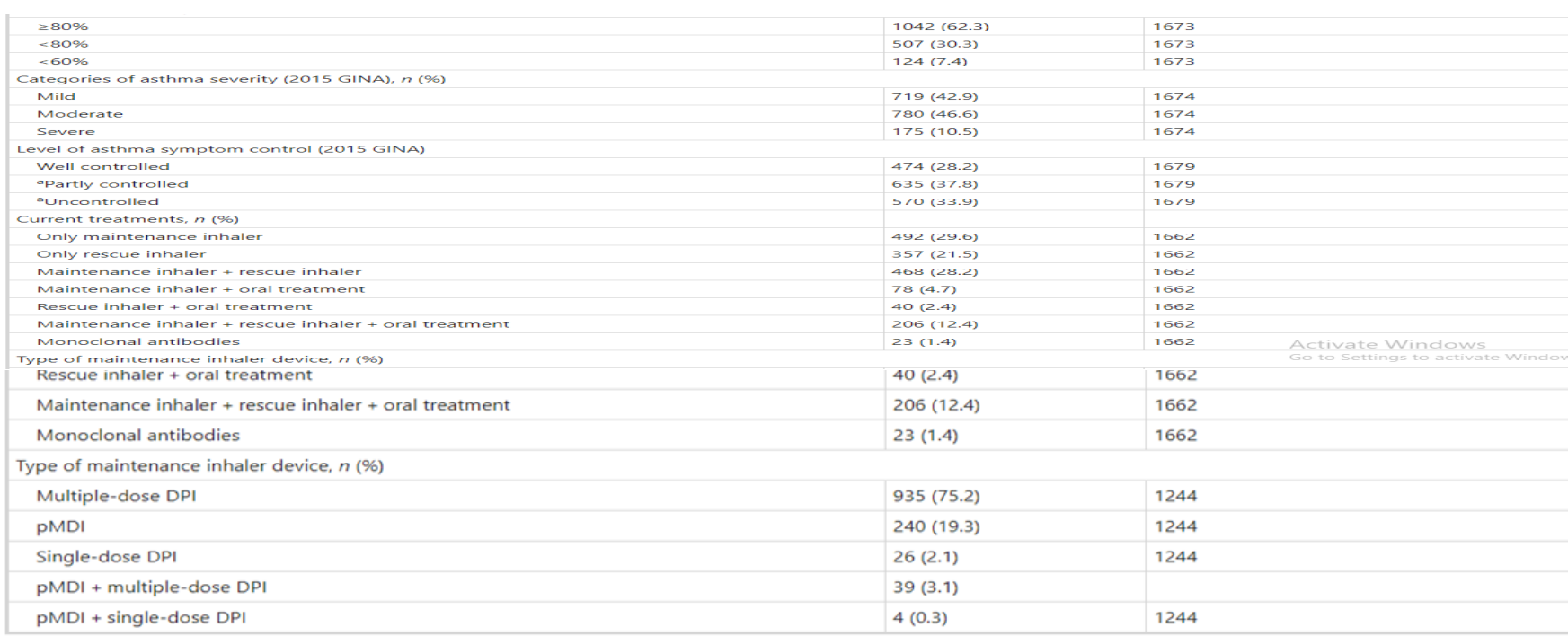

$D P I$ dry powder inhaler, $F E V_{l}$ forced expiratory volume in $1 \mathrm{~s}$, GINA Global Initiative for Asthma, $P E F$ peak expiratory flow, $p M D I$ pressurized metered-dose inhaler

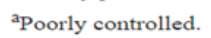

According to the recommendations of the Global Initiative for Asthma (GINA), 35.9\% of patients had a prescription that was insufficient or inadequate (Table 2). GINA 1-5 steps were considered in order to determine whether the prescription was adequate or not. The maintenance treatment of the patients was compared to their previous exacerbations and current symptoms. According to the Asthma Control Test (ACT), 82.5 percent of patients with inadequate prescriptions had poorly controlled (partly/uncontrolled) asthma, whereas 56.3 percent of patients with adequate treatment had poorly controlled asthma (odds ratio (OR) 3.65, 95 percent confidence interval (CI): 2.87-4.65, p 0.0001; Table 3) [46].

\begin{tabular}{|c|c|c|}
\hline Factor & $n(\%)$ & Number of patients evaluated \\
\hline \multicolumn{3}{|c|}{ Inadequate prescription (GINA) } \\
\hline res & $604(35.9)$ & 1681 \\
\hline No & $1077(64.1)$ & 1681 \\
\hline \multicolumn{3}{|c|}{ Adherence according to Morisky-Green questionnaire } \\
\hline Adherent & $522(31.5)$ & 1658 \\
\hline Non-adherent & $1136(68.5)$ & 1658 \\
\hline \multicolumn{3}{|c|}{ Adherence according to TAl } \\
\hline Adherent & $381(23.2)$ & 1639 \\
\hline Non-adherent & $1258(76.8)$ & 1639 \\
\hline No errors & $1394(83.0)$ & 1680 \\
\hline$\geq 1$ error & $286(17.0)$ & 1680 \\
\hline
\end{tabular}

In terms of treatment adherence, the Test of Adherence to Inhalers (TAI) questionnaire revealed that $76.8 \%$ of patients had poor adherence, while the Morisky-Green (MG) questionnaire revealed that 68.5 percent of patients had poor adherence (Table 2). Furthermore, according to the ACT, $68.8 \%$ of patients with poor adherence had poorly managed asthma, whereas 55.1 percent of patients with strong adherence had poorly controlled asthma (OR 1.8, 95 percent CI: 1.42-2.27, p 0.0001; Table 3). According to the extended TAI test, nearly $17 \%$ of patients exhibited at least one major error in inhaler technique (errors in the use of the device that jeopardize the effectiveness of inhaled medication) (Table 2). According to the ACT, 83.2 percent of patients with critical inhaler errors had poorly managed asthma, compared to 62.1 percent of patients with poorly controlled asthma and no critical inhaler errors (OR 3.03, 95 percent CI: 2.18-4.21, p 0.0001; Table 3). Misuse rates varied depending on whether the device was a pressurized metered-dose inhaler (pMDI) or a dry powder inhaler (DPI). As a result (Table 4), EH users had a much lower need for technique adjustment than other DPI users (p 0.0001; Table 4) [47-50].

Table 4: Number of critical mistakes and need of technique adjustment according to DPI device. From:Prevalence of modifiable factors limiting treatment efficacy of poorly controlled asthma patients : EFIMERA observational study

\begin{tabular}{|l|l|l|l|}
\hline $\begin{array}{l}\text { DPI } \\
\text { device }\end{array}$ & $\begin{array}{l}\text { Critical technique mistakes, } \boldsymbol{n} \\
(\%)\end{array}$ & $\begin{array}{l}\text { Need of technique adjustment, } \\
(\%)\end{array}$ & $\begin{array}{l}\text { Number of patients } \\
\text { evaluated }\end{array}$ \\
\hline Accuhaler & $30(19.5)$ & $106(68.8)$ & 154 \\
\hline Easyhaler & $13(10.3)$ & $43(34.4)$ & 126 \\
\hline Nexthaler & $17(16.0)$ & $52(51.5 \%)$ & 106 \\
\hline Turbuhaler & $36(17.5)$ & $120(58.3 \%)$ & 206 \\
\hline
\end{tabular}

$D P I$ dry powder inhaler. 
Each of these risk variables (insufficient prescription, poor adherence, and inhaler abuse) had a statistically significant effect on asthma control ( $\mathrm{p}$ 0.0001; Table 3). Furthermore, having a higher number of risk factors was linked to having poorly controlled asthma, with a maximum of 93 percent for the ACT and 100 percent for the GINA if all three problems were present, and 46 percent for the ACT and 54 percent for the GINA if none were present. When the GINA score was compared to the ACT questionnaire score, there was a moderate agreement (Kappa $=0.458 ; \mathrm{Rho}=0.709 ; \mathrm{r} 2=0.503)$. Supplementary Tables 1 and 2 and Supplementary Figs 1 and 2 show the relevant tables for the GINA asthma control, which are quite similar to the ACT control.

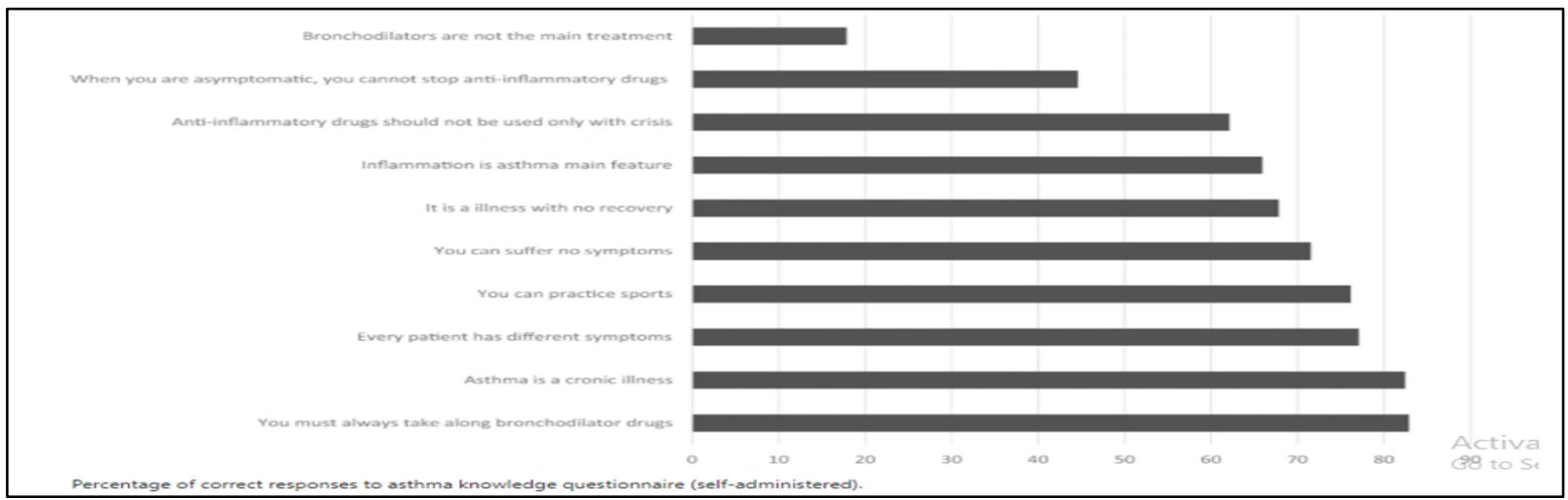

Figure 1: Asthama knowledge questionnaire

From:Prevalence of modifable factors liliting efficacy of poority controlled asthma patients : EFIMERA observational study

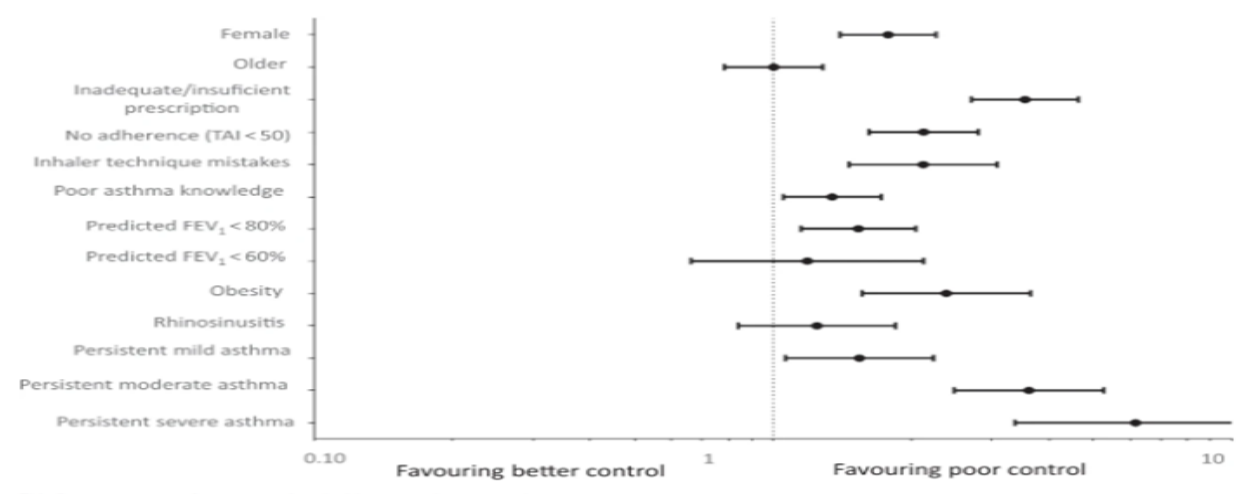

Figure 2: Binary logistic regression model with poor asthma control $(\mathrm{ACT}<21)$ as dependent variable. From: Prevalence of modifiable limiting treatment efficacy of poorly controlled asthma patients EFIMERA study

\section{Discussion}

Despite years of asthma guidelines implementation, poor asthma control was found to be highly linked to modifiable variables associated with medication failure in this investigation [60]. According to a recent study, although numerous factors may be implicated in poor asthma control, three factors appear to be the key causes of poor asthma control in primary care. Inadequate prescriptions, poor medication adherence, and poor inhaler technique6, $9,13,14,15$ are all factors. Obesity has a negative impact on asthma control, and preliminary evidence suggests that losing weight can improve asthma control and quality of life16. However, whereas diet-induced weight loss is associated with a slew of general health benefits, there is currently little evidence on asthma control; as a result, the authors did not include this factor among the modifiable ones. According to the GINA and the ACT, 71.7 and 65.7 percent of patients in our study had inadequate symptom control, respectively. Several studies in primary care have been undertaken in recent years, with various measured variables and designs16. Despite their differences, they all had a tendency to have poor asthma control. Calvo et al.19, in a recent Spanish article, revealed inadequate asthma control (ACT 20) in 638 asthmatic patients, ranging from 23.4 to 75.6 percent, depending on the patients' medical consultation. Almost half of the patients had poor control on average. According to the authors of another study20, 45 percent of asthmatic patients in Spain who received any sort of treatment had uncontrolled asthma. Other European countries' asthma control isn't much better: a recent Swedish primary care research found that 53.6 percent of patients had 
uncontrolled asthma (600 doses of short-acting beta agonists and/or 1 exacerbation each year). 21. The Asthma Control Questionnaire was used to assess asthma control in the European LIAISON study22, and the percentage of patients with partially or poorly managed asthma was 56.5 among the 12 nations that took part in the study. In the United States, a similar situation exists: 50 percent of patients who visited primary care for a non-respiratory consultation had uncontrolled asthma (ACT 19)23. When compared to our study, most studies reveal a little lower percentage of poorly managed individuals, which could be due to selection bias, as patients sent to specialist care are not expected to be asymptomatic. More than a third of our patients received inadequate treatment at the time of referral from primary care, which was linked to poor asthma control. Both doctors and patients have a tendency to underestimate the severity of asthma, which may explain why many people are undertreated. Lack of time and financial resources are some of the reasons for inadequate asthma management in primary care24, despite the fact that it is well known that poor diagnosis and treatment have a negative impact on patients' health 25 , resulting in increased care demand and expense. In this regard, the ACT was developed as a tool for detecting poorly controlled asthma and, as a result, identifying those patients who needed the most effective treatment. When a clinician uses it on a regular basis, it has been found to allow for better treatment adjustments. Electronic devices, which could be the gold standard8, (they are an objective approach to assess patients' adherence), are the best strategy for evaluating adherence, but they are expensive and difficult to use for many patients. As a result, self-reports appear to be the most cost-effective way to assess it7, despite the fact that patients are sometimes unwilling to disclose poor adherence29. Two adherence questionnaires were employed in this study, and the TAI questionnaire appears to be more sensitive than the MG one (76 and 68.5 percent, respectively, have a poor adherence). The TAI has also been demonstrated to have a greater association with patient actual adherence 30 . Furthermore, when asthma control is assessed using the ACT punctuation and GINA criteria, a statistically significant relationship is found. Similarly, in the REcognize Asthma and LInk to Symptoms and Experience (REALISE) study11, nearly half of the patients had poor adherence to treatment, and in the LIAISON study, patients with poorly controlled asthma had a higher rate of low adherence (according to the MG) than those with well-controlled asthma22. To emphasize the significance of strict adherence, It should be noted that its absence is connected to a higher risk of asthma exacerbations, increased use of oral corticosteroids, the necessity for ER visits and/or hospitalization, deterioration of forced expiratory volume in $1 \mathrm{~s}$ values 29,31 , and lastly, higher expenses and poor quality of life7. Every visit, strategies to promote adherence have been investigated, such as reviewing the inhaler usage method as well as patient adherence. Electronic reminders should also be employed because they are highly effective. 29,30,32,33. In primary care, it has been proven that an educational program can help with adherence, cost control, and cost reduction. After proper training, the program should include medical practitioners as well as nursing services34. In terms of the third major cause of poorly managed asthma, insufficient inhaler technique, this study found that $17 \%$ of patients referred from primary care make crucial errors, which is linked to poor asthma control (GINA OR 4.76; ACT OR 3.03). Serious inhaler technique errors are those that have the potential to impede medication uptake and distribution to the lungs. Although the percentage of key errors in some studies (ranging from 50 to 90 percent) 35 is higher than in ours, this step is unquestionably important in achieving asthma control. Poor inhaler technique has been linked to an increase in symptoms 36 , the need for hospitalization 12, and, most importantly, less effective asthma control. In a Dutch study, between $47.7 \%$ and 64.9 percent of patients referred to primary care had inhaler abuse; a pragmatic intervention improved this factor significantly37. Between inhaler devices, the percentage of major mistakes varies greatly. Patients performed better with the DPI devices than the MDIs in our trial, as expected. When compared to other DPIs, EH was related with a lower number of critical errors (Turbuhaler, Nexthaler, Accuhaler). Previous investigations have shown that the EH device has a higher rate of acceptance and satisfaction38,39, which supports this conclusion. Furthermore, some studies suggest that an explanation of how to use an inhaler, as well as a practical demonstration of patient abilities with the device, are beneficial. Some publications, for example, recommend that before a patient is discharged from the Emergency Department, an explanation of inhaler technique be given. Inadequate prescriptions, treatment adherence, and inhaler technique all contribute to the fact that 73.3 percent of patients have poorly managed asthma (according to GINA criteria) and 65.7 percent of patients have poorly controlled asthma (according to the ACT questionnaire). As already stated These three characteristics are critical for asthma control5,6,9,24, and as additional risk factors are present, control worsens, ranging from 58.4 percent of poor control (ACT 20) when one condition is implicated to 93.5 percent when all conditions are implicated (or 54-100 percent using the GINA criteria). Although the GINA could detect a higher proportion of under controlled individuals than the ACT, our investigation appears to demonstrate such a concordance between the ACT and the GINA criteria for asthma control. Most patients assume that bronchodilators are the major medication for treating asthma and that anti-inflammatory treatment can be stopped during remission times, which is not encouraging. When asthma comprehension is looked at as a predictor of poor asthma control using a binary logistic regression, it appears to be an independent predictor. Patients' adherence is likely influenced by these concerns: in the REALISE study11, half of the patients did not take their maintenance drugs correctly. Even when they experienced severe and persistent symptoms, nearly half of individuals in another study10 reported their asthma was well managed. Patients' understanding and, as a result, adherence to treatment could be improved by educational initiatives. 
Our findings reveal that poor asthma management, adherence to therapy, inhaler technique, and asthma knowledge are key factors resulting in poorer asthma control at the primary care level. When referred to a Specialist, many patients do not obtain proper treatment and adherence to therapy is poor. Furthermore, individuals who make major errors in inhaler technique are a common occurrence [79].

\section{Conclusion}

This study shows that there is still room for improvement by focusing on these modifiable factors that appear to be key opportunities for improving asthma management at the primary care level, such as optimizing therapy, retraining on inhaler technique, and developing new tools to improve adherence to treatment.

\section{References}

1. To, T. et al. Global asthma prevalence in adults: findings from the cross-sectional world health survey. BMC Public Health 12, 204 (2012). PubMed PubMed Central Google Scholar

2. GBD 2013 Mortality and Causes of Death Collaborators. Global, regional, and national age-sex specific all-cause and cause-specific mortality for 240 causes of death, 1990-2013: a systematic analysis for the Global Burden of Disease Study 2013. Lancet 385, 117-171 (2015). Google Scholar

3. Nguyen, H. V. et al. Association between asthma control and asthma cost: Results from a longitudinal study in a primary care setting. Respirology 22, 454 459 (2017). PubMed Google Scholar

4. Rui, P., Kang, K. \& Ashman, J. J. National Hospital Ambulatory Medical Care Survey: 2016 emergency department summary tables. https://www.cdc.gov/nchs/data/nhamcs/web_tables/2 016_ed_web_tables.pdf (2016).

5. Dougherty, R. H. \& Fahy, J. V. Acute exacerbations of asthma: epidemiology, biology and the exacerbation-prone phenotype. Clin. Exp. Allergy 39, 193-202 (2009). CAS PubMed PubMed Central Google Scholar

6. Menzies-Gow, A. \& Chiu, G. Perceptions of asthma control in the United Kingdom: a cross-sectional study comparing patient and healthcare professionals' perceptions of asthma control with validated ACT scores. NPJ Prim. Care Respir. Med. 27, 48 (2017). PubMed PubMed Central Google Scholar

7. Engelkes, M., Janssens, H. M., de Jongste, J. C., Sturkenboom, M. C. J. M. \& Verhamme, K. M. C. Medication adherence and the risk of severe asthma exacerbations: a systematic review. Eur. Respir. J. 45, 396-407 (2015). PubMed Google Scholar

8. Boulet, L.-P., Vervloet, D., Magar, Y. \& Foster, J. M. Adherence: the goal to control asthma. Clin. Chest Med. 33, 405-417 (2012). PubMed Google Scholar

9. Lang, D. M. Severe asthma: epidemiology, burden of illness, and heterogeneity. Allergy Asthma Proc. 36, 418-424 (2015). PubMed Google Scholar
10. Rabe, K. F., Vermeire, P. A., Soriano, J. B. \& Maier, W. C. Clinical management of asthma in 1999: the Asthma Insights and Reality in Europe (AIRE) study. Eur. Respir. J. 16, 802-807 (2000). CAS PubMed Google Scholar

11. Price, D., Fletcher, M. \& van der Molen, T. Asthma control and management in 8,000 European patients: the REcognise Asthma and LInk to Symptoms and Experience (REALISE) survey. NPJ Prim. Care Respir. Med. 24, 14009 (2014). PubMed PubMed Central Google Scholar

12. Westerik, J. A. M. et al. Characteristics of patients making serious inhaler errors with a dry powder inhaler and association with asthma-related events in a primary care setting. J. Asthma 53, 321-329 (2016). PubMed PubMed Central Google Scholar

13. Van Ganse, E. \& Price, D. Respiratory medication adherence: toward a common language and a shared vision. J. Allergy Clin. Immunol. Pract. 4, 799-801 (2016). PubMed Google Scholar

14. Walia, M. et al. Assessment of inhalation technique and determinants of incorrect performance among children with asthma. Pediatr. Pulmonol. 41, 10821087 (2006). PubMed Google Scholar

15. Boulet, L.-P. et al. Benefits of an asthma education program provided at primary care sites on asthma outcomes. Respir. Med. 109, 991-1000 (2015). PubMed Google Scholar

16. Peters, U., Dixon, A. E. \& Forno, E. Obesity and asthma. J. Allergy Clin. Immunol. 141, 1169-1179 (2018). PubMed PubMed Central Google Scholar

17. Özbey, Ü. et al. The effects of diet-induced weight loss on asthma control and quality of life in obese adults with asthma: a randomized controlled trial. J. Asthma 57, 618-626 (2020). PubMed Google Scholar

18. Stoodley, I., Williams, L., Thompson, C., Scott, H. \& Wood, L. Evidence for lifestyle interventions in asthma. Breathe (Sheff.) 15, e50-e61 (2019). Google Scholar

19. Calvo, E., Trigueros, J. A., López, A. \& Sánchez, G. [Asthma control in patients attending primary care in Spain (Actis study)]. Aten. Primaria 49, 586-592 (2017). PubMed PubMed Central Google Scholar

20. Demoly, P. et al. Prevalence of asthma control among adults in France, Germany, Italy, Spain and the UK. Eur. Respir. Rev. 18, 105-112 (2009). CAS PubMed Google Scholar

21. Larsson, K. et al. Prevalence and management of severe asthma in primary care: an observational cohort study in Sweden (PACEHR). Respir. Res. 19, 12 (2018). PubMed PubMed Central Google Scholar

22. Braido, F. et al. Determinants and impact of suboptimal asthma control in Europe: The INTERNATIONAL CROSS-SECTIONAL AND LONGITUDINAL ASSESSMENT ON ASTHMA CONTROL (LIAISON) study. Respir. Res. 17, 51 (2016). PubMed PubMed Central Google Scholar 
23. Mintz, M. et al. Assessment of asthma control in primary care. Curr. Med. Res. Opin. 25, 2523-2531 (2009). CAS PubMed Google Scholar

24. Rank, M. A., Bertram, S., Wollan, P., Yawn, R. A. \& Yawn, B. P. Comparing the Asthma APGAR system and the Asthma Control TestTM in a multicenter primary care sample. Mayo Clin. Proc. 89, 917-925 (2014). PubMed Google Scholar

25. Pakhale, S., Sumner, A., Coyle, D., Vandemheen, K. \& Aaron, S. (Correcting) misdiagnoses of asthma: a cost effectiveness analysis. BMC Pulm. Med. 11, 27 (2011). PubMed PubMed Central Google Scholar

26. García-Giralda, L., Quiralte Enríquez, J., Sánchez Herrero, M. G., López Peral, J. C. \& Aracil, J. [Impact of administering the Asthma Control Test questionnaire on rating asthma control in primary health care]. Aten. Primaria 45, 522-527 (2013). PubMed PubMed Central Google Scholar

27. Weinstein, A. G. Improving adherence to asthma therapies. Curr. Opin. Pulm. Med. 21, 86-94 (2015). CAS PubMed Google Scholar

28. Vrijens, B. et al. What we mean when we talk about adherence in respiratory medicine. J. Allergy Clin. Immunol. Pract. 4, 802-812 (2016). PubMed Google Scholar

29. Anderson, W. C. Incorporating technology to advance asthma controller adherence. Curr. Opin. Allergy Clin. Immunol. 17, 153-159 (2017). PubMed Google Scholar

30. Bidwal, M., Lor, K., Yu, J. \& Ip, E. Evaluation of asthma medication adherence rates and strategies to improve adherence in the underserved population at a Federally Qualified Health Center. Res. Soc. Adm. Pharm. RSAP 13, 759-766 (2017). Google Scholar

31. Dima, A. L. et al. Asthma inhaler adherence determinants in adults: systematic review of observational data. Eur. Respir. J. 45, 994-1018 (2015). PubMed Google Scholar

32. Mokoka, M. C. et al. In patients with severe uncontrolled asthma, does knowledge of adherence and inhaler technique using electronic monitoring improve clinical decision making? A protocol for a randomised controlled trial. BMJ Open 7, e015367 (2017). PubMed PubMed Central Google Scholar

33. Foster, J. M. et al. Inhaler reminders improve adherence with controller treatment in primary care patients with asthma. J. Allergy Clin. Immunol. 134, 1260-1268.e3 (2014). PubMed Google Scholar

34. Haahtela, T. et al. The Finnish experience to save asthma costs by improving care in 1987-2013. J. Allergy Clin. Immunol. 139, 408-414.e2 (2017). PubMed Google Scholar

35. Melani, A. S. et al. Inhaler mishandling remains common in real life and is associated with reduced disease control. Respir. Med. 105, 930-938 (2011). PubMed Google Scholar

36. Bartolo, K. et al. Predictors of correct technique in patients using pressurized metered dose inhalers.
BMC Pulm. Med. 17, 47 (2017). PubMed PubMed Central Google Scholar

37. Metting, E. I. et al. Feasibility and effectiveness of an asthma/COPD service for primary care: a crosssectional baseline description and longitudinal results. NPJ Prim. Care Respir. Med. 25, 14101 (2015). PubMed PubMed Central Google Scholar

38. Chrystyn, H. \& Price, D. Not all asthma inhalers are the same: factors to consider when prescribing an inhaler. Prim. Care Respir. J. 18, 243-249 (2009). PubMed PubMed Central Google Scholar

39. Giner, J. et al. [Patient preference in the choice of dry powder inhalers]. Arch. Bronconeumol.

40. 106-109 (2004). CAS PubMed Google Scholar 40. Plaza, V. et al. Impact of patient satisfaction with his or her inhaler on adherence and asthma control. Allergy Asthma Proc. 39, 437-444 (2018). PubMed PubMed Central Google Scholar

41. Valero, A. et al. Asthma patient satisfaction with different dry powder inhalers. Expert Rev. Respir. Med. 13, 133-138 (2019). CAS PubMed Google Scholar

42. Schatz, $M$. et al. Recommendations for the management and follow-up of asthma exacerbations. Introduction. J. Emerg. Med. 37, S1-S5 (2009). PubMed Google Scholar

43. Vincken, W. et al. Spacer devices for inhaled therapy: why use them, and how? ERJ Open Res. 4, 000652018 (2018).

44. The Global Initiative for Asthma (GINA). Pocket guide for asthma management and prevention. https://ginasthma.org/wpcontent/uploads/2016/10/WMS-Spanish-PocketGuide-GINA-2016-v1.1.pdf (2015).

45. Morisky, D. E., Green, L. W. \& Levine, D. M. Concurrent and predictive validity of a self-reported measure of medication adherence. Med. Care 24, 6774 (1986). CAS PubMed Google Scholar

46. Plaza, V. et al. Validation of the 'Test of the Adherence to Inhalers' (TAI) for asthma and COPD patients. J. Aerosol Med. Pulm. Drug Deliv. 29, 142152 (2016). PubMed PubMed Central Google Scholar

47. GEMA Educadores. Manual del educador en asma. Grupo español para el manejo del asma. http://www.seicap.es/gema-educadores_30428.pdf (2012).

48. Nathan, R. A. et al. Development of the asthma control test: a survey for assessing asthma control. J. Allergy Clin. Immunol. 113, 59-65 (2004). PubMed Google Scholar

49. Akinkugbe AA, Slade GD, Barritt AS, Cole SR, Offenbacher S, Petersmann A, Kocher T, Lerch MM, Mayerle J, Volzke H, et al. 2017. Periodontitis and non-alcoholic fatty liver disease, a population-based cohort investigation in the study of health in Pomerania. J Clin Periodontol. 44(11):1077-1087.

50. Anglemyer A, Horvath HT, Bero L. 2014. Healthcare outcomes assessed with observational study designs 
compared with those assessed in randomized trials. Cochrane Database Syst Rev. (4):MR000034.Beck J, Drake C. 1975. Some epidemiologic evidence on the etiology of caries. Community Dent Oral Epidemiol. 3(5):223-227.

51. Beck JD, Moss KL, Morelli T, Offenbacher S. 2018. In search of appropri-ate measures of periodontal status: the periodontal profile phenotype $(\mathrm{p}(3))$ system. J Periodontol. 89(2):166-175.

52. Beck JD, Sharp T, Koch GG, Offenbacher S. 1997. A 5 -year study of attach-ment loss and tooth loss in community-dwelling older adults. J Periodontal Res. 32(6):516-523.

53. Brown LF, Beck JD, Rozier RG. 1994. Incidence of attachment loss in commu-nity-dwelling older adults. J Periodontol. 65(4):316-323.

54. Cepeda MS, Weinstein R, Blacketer C, Lynch MC. 2017. Association of floss-ing/inter-dental cleaning and periodontitis in adults. J Clin Periodontol. 44(9):866-871.

55. Curtis MA, Zenobia C, Darveau RP. 2011. The relationship of the oral micro-biotia to periodontal health and disease. Cell Host Microbe. 10(4):302306.

56. Delwel S, Binnekade TT, Perez RS, Hertogh CM, Scherder EJ, Lobbezoo F. 2017. Oral health and orofacial pain in older people with dementia: a systematic review with focus on dental hard tissues. Clin Oral Investig. 21(1):17-32.

57. Dolan TA, Atchison KA. 1993. Implications of access, utilization and need for oral health care by the non-institutionalized and institutionalized elderly on the dental delivery system. J Dent Educ. 57(12):876887.

58. Drake CW, Hunt RJ, Beck JD, Koch GG. 1994. Eighteen-month coronal caries incidence in North Carolina older adults. J Public Health Dent. 54(1):2430.

59. Ellefsen B, Holm-Pedersen P, Morse DE, Schroll M, Andersen BB, Waldemar G. 2009. Assessing caries increments in elderly patients with and without dementia: a one-year follow-up study. J Am Dent Assoc. 140(11):1392-1400.

60. Feres M, Teles F, Teles R, Figueiredo LC, Faveri M. 2016. The subgingival periodontal microbiota of the aging mouth. Periodontol 2000. 72(1):30-53.

61. Graves RC, Beck JD, Disney JA, Drake CW. 1992. Root caries prevalence in Black and White North Carolina adults over age 65. J Public Health Dent. 52(2):94-101.

62. Guggenheim B, Guggenheim M, Gmur R, Giertsen E, Thurnheer T. 2004. Application of the Zurich

75. Morelli T, Moss KL, Beck J, Preisser JS, Wu D, Divaris K, Offenbacher S. 2017. Derivation and validation of the periodontal and tooth profile classification system for patient stratification. J Periodontol. 88(2):153-165. biofilm model to problems of cariology. Caries Res. 38(3):212-222.

63. Hajishengallis G, Darveau RP, Curtis MA. 2012. The keystone-pathogen hypothesis. Nat Rev Microbiol. 10(10):717-725.

64. Holm-Pedersen P, Schultz-Larsen $\mathrm{K}$, Christiansen $\mathrm{N}$, Avlund K. 2008. Tooth loss and subsequent disability and mortality in old age. J Am Geriatr Soc. 56(3):429435.

65. Hujoel PP, Cunha-Cruz J, Banting DW, Loesche WJ. 2006. Dental flossing and interproximal caries: a systematic review. J Dent Res. 85(4):298-305.

66. Hunt RJ, Drake CW, Beck JD. 1992. Streptococcus mutans, lactobacilli, and caries experience in older adults. Spec Care Dentist. 12(4):149-152.

67. Jepsen S, Blanco J, Buchalla W, Carvalho JC, Dietrich T, Dorfer C, Eaton KA, Figuero E, Frencken JE, Graziani F, et al. 2017. Prevention and control of den-tal caries and periodontal diseases at individual and population level: consen-sus report of group 3 of joint EFP/ORCA workshop on the boundaries between caries and periodontal diseases. J Clin Periodontol. 44 Suppl 18:S85-S93.

68. Jiao Y, Darzi Y, Tawaratsumida K, Marchesan JT, Hasegawa M, Moon H, Chen GY, Nunez G, Giannobile WV, Raes J, et al. 2013. Induction of bone loss by pathobiont-mediated Nod1 signaling in the oral cavity. Cell Host Microbe. 13(5):595-601.

69. Lee JH, Yi SK, Kim SY, Kim JS, Kim HN, Jeong SH, Kim JB. 2019. Factors related to the number of existing teeth among korean adults aged 55-79 years. Int J Environ Res Public Health. 16(20). pii: E3927.

70. Listgarten MA, Mayo HE, Tremblay R. 1975. Development of dental plaque on epoxy resin crowns in man. A light and electron microscopic study. $\mathrm{J}$ Periodontol. 46(1):10-26.

71. Loe H, Theilade E, Jensen SB. 1965. Experimental gingivitis in man. J Periodontol. 36:177-187.

72. Marchesan JT, Morelli T, Moss K, Preisser JS, Zandona AF, Offenbacher S, Beck J. 2018. Interdental cleaning is associated with decreased oral disease prevalence. J Dent Res. 97(7):773-778.

73. Marcus SE, Drury TF, Brown LJ, Zion GR. 1996. Tooth retention and tooth loss in the permanent dentition of adults: United States, 1988-1991. J Dent Res. 75 Spec No:684-695.

74. Mc Cord KA, Al-Shahi Salman R, Treweek S, Gardner H, Strech D, Whiteley W, Ioannidis JPA, Hemkens LG. 2018. Routinely collected data for randomized trials: promises, barriers, and implications. Trials. 19(1):29.

76. Morelli T, Moss KL, Preisser JS, Beck JD, Divaris K, Wu D, Offenbacher S. 2018. Periodontal profile classes predict periodontal disease progression and tooth loss. J Periodontol. 89(2):148-156.

77. Moss KL, Oh ES, Fisher E, Beck JD, Offenbacher S, White RP Jr. 2009. Third molars and periodontal 
pathologic findings in middle-age and older americans. J Oral Maxillofac Surg. 67(12):2592-2598.

78. Sanz M, Beighton D, Curtis MA, Cury JA, Dige I, Dommisch H, Ellwood R, Giacaman RA, Herrera D, Herzberg MC, et al. 2017. Role of microbial biofilms in the maintenance of oral health and in the development of dental caries and periodontal diseases. Consensus report of group 1 of the joint EFP/ORCA workshop on the boundaries between caries and periodontal disease. J Clin Periodontol. 44 Suppl 18:S5-S11.

79. Socransky SS, Haffajee AD. 2005. Periodontal microbial ecology. Periodontol 2000. 38:135-187. 